\title{
A critical analysis of information and communications technology adoption: The strategy-as-practice perspective
}

\author{
Authors: \\ Neelambal M. Govender ${ }^{1}$ \\ Marius Pretorius ${ }^{1}$ \\ Affiliations: \\ ${ }^{1}$ Faculty of Economic and \\ Management Sciences, \\ University of Pretoria, \\ South Africa

\section{Correspondence to:} \\ Neelambal Govender \\ Email: \\ neels.govender@resbank. \\ co.za \\ Postal address: \\ PO Box 30532, Sunnyside \\ 0132, South Africa

\section{Dates:} \\ Received: 03 Oct. 2013 \\ Accepted: 09 Dec. 2014 \\ Published: 05 May 2015 \\ How to cite this article: \\ Govender, N.M. \& Pretorius, \\ M., 2015, 'A critical \\ analysis of information and \\ communications technology \\ adoption: The strategy-as- \\ practice perspective', Acta \\ Commercii 15(1), Art. \#229, \\ 13 pages. http://dx.doi. \\ org/10.4102/ac.v15i1.229

\section{Copyright:} \\ (C) 2015. The Authors. \\ Licensee: AOSIS \\ OpenJournals. This work is \\ licensed under the Creative \\ Commons Attribution \\ License.
}

Purpose: The ubiquitous pace of innovation is spawning a multitude of information and communications technology (ICT) products that are both redefining the manner in which organisations operate and have the potential to engender organisations with strategic advantage through the adoption of these products. However, the challenges that this presents to organisations include developing agile strategies that cater for market instabilities, determining what technology to adopt and ensuring that the appropriate technology is adopted. Thus, the purpose of this article is to perform a critical analysis of ICT adoption in an attempt to determine the influence that the pace of technology has on organisations in their endeavour to stay abreast of their market environment and to develop a comprehensive ICT adoption framework.

Design/methodology/approach: This is exploratory research that concentrates on ICT adoption studied through the strategy-as-practice lens. Through critical analysis, the scientific literature was analysed to determine ICT adoption factors and to gain a better understanding of ICT adoption in the modern context. The principles of grounded theory were applied where repetitive reading of selected articles made it possible to identify factors that are associated with ICT adoption.

Findings: The study identified three key factors of ICT adoption, namely 'external', 'innovation' and 'organisational'. A number of ICT adoption characteristics were identified which were categorised against the three factors. In addition, the study identified critical management challenges associated with ICT innovation and the adoption thereof in the modern business context.

Research limitations/implications: The proposed ICT adoption framework is based on scientific literature only and no popular writings, blogs or forums were included.

Practical implications: Strategists need to understand that developing agile strategies involves more than discipline; it embraces an in-depth understanding of ICT adoption factors, insight into the daily operations of managers and an awareness of innovations in ICT.

Originality/value: The article aims to enable organisations to better understand the effects of ICT innovation and the influence this has on management roles. Additionally, it presents a comprehensive ICT adoption framework that can aid strategists in understanding the factors that influence ICT adoption.

\section{Introduction}

Information and communications technology (ICT) is gaining prominence as a key contributor that is revolutionising the way in which organisations conduct business. This is quite evident from the manner in which ICT is shaping business outcomes through social media, big data, mobile technology and cloud computing. The speed of technology advancement and the resulting innovations are the main contributors to environmental change and the cause of its instability. If technology innovations are seen as the fuel for change, then the adoption thereof may be viewed as the vehicle used by management to participate in this world of constant change and its diffusion accepted as the driver for success within organisations. ICT plays an enormous role in business today and there is little disagreement about its strategic business importance (Adner 2004:25; Bakos \& Treacy 1986:107). Many authors have focused on the strategic importance of ICT and the need to align both business and ICT strategies for optimal benefit realisation. Although ICT and business strategy alignment is strategically important, of equal importance are the strategic decisions pertaining to the adoption of ICT.

Strategy is a plan that organisations intend to follow in order to achieve certain desired objectives that provide an advantage over their rivals. More importantly, it refers to the organisation's 
intentions and the activities it pursues for sustained existence to embrace its market environment. Strategic management deals with how organisations achieve advantage through these strategies (Bitar \& Hafsi 2007:403). Since the early eighties, technology has been gaining momentum as a strategic variable and has since become a significant contributor towards the field of strategic management, providing a dominant role in the creation of corporate strategies (Friar \& Horwitch 1985:147).

Over the past decade, market environments have been disrupted mostly by ICT innovations and organisations need to evolve to adapt to these changes by creating organic structures that align with their environment (Andersen 2001:105; Damanpour \& Gopalakrishnan 1998). In order to develop robust strategies and ultimately sustain their survival, organisations are under extreme pressure to change or adapt quickly to their environments (Ghobakhloo et al. 2012:37). The question weighing heavily on executives' minds is whether to change or alter strategies (Ghobakhloo et al. 2012). According to Dutta and Bilbao-Osorio (2012), the global economy is not only experiencing turbulence but has also become increasingly hyperconnected. Complicating matters even further is that traditional models used by organisations to develop strategies that support business operations have become inadequate to respond timeously to market stimuli. Thus, the strategy approach required for ICT adoption is one that can potentially address instability experienced in the contemporary environment, whilst being agile and flexible to respond to the business needs.

The speed of change brought on by ICT innovation means faster business response is required to meet market changes. In order for organisations to address this response, managers who serve as thought leaders need to find new ways of meeting this challenge. Finding answers to this challenge may help organisations better prepare to handle the dynamics in their market environment and in doing so develop advantageous strategies. Given that contemporary organisations are in uncharted waters, a paradigm shift is required where strategymaking is concerned. A new school of thought provides this paradigm shift by focusing on strategy as an 'activity' rather than a 'process' (Jarratt \& Stiles 2010:38; Whittington et al. 2006:618). The critical thinking this paradigm brings to strategy-making is that unlike the traditional approach that focuses on the macro aspects of strategy, this approach deals with the social human practices of strategy (Vaara \& Whittington 2012:2). Given the importance of ICT adoption as a means to align business strategies with its environment, the focus of this article is to analyse critically the aspects of ICT adoption, the outcome of which is to present a comprehensive framework of ICT adoption factors. Drawing from the micro lens of strategy-as-practice, the article examines these factors to gain insight into the activities of strategising for ICT adoption.

The article proceeds as follows: the next section presents the research question that is addressed in this article. This is followed by a literature review of ICT adoption and associated challenges experienced in the modern business context, making use of the practice lens to expand on key issues. This is followed by the findings on ICT adoption factors, which are presented in the form of an adoption framework. The article concludes with a discussion on the findings and recommends future research opportunities.

\section{Research question}

The principal aim of this article is to focus on the challenges that ICT adoption presents to organisations in the modern business context, analyse current literature to identify ICT adoption factors and to develop an ICT adoption framework. The outcome of this is to improve the general understanding of how strategising for ICT adoption transpires in the modern economy. In an endeavour to increase this understanding, the article focuses on the following research question:

What are the ICT adoption factors that shape decisions in the contemporary business environment?

\section{Literature study Activity theory lens}

Strategy-as-practice (s-as-p) provides a unique manner in which to understand strategic management, managerial activities and decision-making. It focuses on the micro level social activities, processes and practices that characterise organisational strategy and strategising (Golsorkhi et al. 2010:1). S-as-p, according to Jarzabkowski, Balogun and Seidl (2007:8), refers to strategising as the 'doing of strategy' and focuses explicitly on human activities. Traditionally, strategy was something that organisations had. However, strategy viewed from a practice perspective is viewed as something that people do (Chia \& MacKay 2007:223; Jarzabkowski 2004:529). Drawing from the s-as-p perspective, ICT adoption activities can provide insight into adoption practices; more importantly, it can provide the basis for future reference in determining how ICT adoption factors influence ICT adoption decisions and how these decisions ultimately shape strategy.

The s-as-p field focuses on three building blocks that make up strategising. These are the practitioners, practices and praxis. According to Whittington (2002:c1), practitioners are the 'workers' (in the context of this study, the managers and implementers of technology adoption), practices are the 'tools' (in the context of this study, the adoption practices) and praxis is the 'work' of strategy (in the context of this study, the work of ICT adoption). Practices are seen as the 'infrastructure through which micro-strategy and strategising occurs' (Jarzabkowski 2003:24). Strategy practitioners are 'actors', those individuals who do the work of strategy; strategy practices are the 'material tools' through which the work gets done and strategy praxis are the 'actions' that meet the objective of the strategy (Jarzabkowski \& Spee 2009:70). $\mathrm{S}$-as-p is concerned with the daily practices of individuals and identifies how these actions influence strategy (Jarzabkowski \& Wilson 2002:358). It is this view that provides valuable insight into the decisions of ICT adoption, which eventually contributes towards the organisation's strategic objective. 


\section{Management in the contemporary environment}

Managers are those individuals who undertake to do the work of strategy and are seen as 'craftspeople' in the process of strategy-making (Whittington et al. 2006:616). Practitioner activities should not be taken lightly because it is the activities of these individuals that contribute towards the formulation of organisation strategies that determine the organisation's survival. Practitioners of strategy should not be viewed only as senior executives for whom strategy is the core focus of their work but rather the term should apply to a wider selection of actors. Although individuals at lower levels within the organisation may not have a title that is as important, nonetheless they are key in filtering information that contributes towards strategising activities. Managers' decisions and activities contribute greatly towards achieving the alignment between an organisation's strategies and the environment within which it operates (Goll, Johnson \& Rasheed 2007:162). The traditional model of strategy formulation is entrenched by a hierarchical structure that is supported by predictable and stable environments, whereas contemporary environments are dynamic, with organisational structures that are supportive of middle and lower level involvement (Mantere \& Vaara 2008:342). When compared to the traditional model, distinct management roles are becoming obsolete because of the impact of ICT innovation on management's decision-making abilities (Drucker 1988:3; Kearns \& Sabherwal 2006:136; Spanos, Prastacos \& Poulymenakou 2002:662). Understanding how organisations react to change requires insight at an individual level (Christensen \& Overdorf 2000:1; Stensaker \& Falkenberg 2007:143).

Managers are involved in a wide range of decision-making activities that are of strategic importance to the organisation (Chapman 2001:63; Hendry 2000:958). Strategic issues become evident from the context within which managers engage daily and can contribute towards the strategic objectives of the organisation (Elter 2004:6). Technological advancement plays a pivotal role in determining organisational success and, as such, organisations have increased their adoption of sophisticated technologies (Zahra \& Covin 1993:451). Technology adoption serves as a vehicle that allows management to participate in a world of constant innovation with strategic benefits. This highlights the value and importance of understanding the context of ICT adoption activities that have the potential to become organisational practices, which eventually shape strategy. The right technology adoption can contribute significantly towards the day-to-day activities of managers. Knowledge of the environment, the need that the technology will address and the skills required for the use of the technology form the source of management decision-making.

Since the advent of technology, there have been many 'latest and greatest' gadgets. Users appear to want the next new thing and they want it now. This is the same for customers and their requirements that managers have to cater for. With the arrival of the Internet, customers are much more knowledgeable, informed and empowered with information. They no longer want cookie-cut products. Customers are demanding a greater involvement and say in the products and services they receive. Managers are faced with the challenge of delivering more personalisation, better adaption, greater customisation and increased value for their products and services in much shorter time frames. This creates a vicious cycle because in catering for these requirements, managers have to look to technology adoption as a possible solution. These requirements have the potential to influence the manner in which activities are performed within the given job context. If decision-making for ICT adoption is influenced by job context then it makes sense that practitioners at different levels may have different viewpoints on what adoption factors are critical. Given this context, what are the key factors that managers need to consider for ICT adoption and what demands does this place on managers' day-to-day activities? This is the key objective that this study hopes to address and in doing so develop a framework listing critical ICT adoption factors.

\section{Information and communications technology adoption and adoption influences on strategy-making}

Gartner (2008) defines innovation as something new to a group or enterprise, something that is not currently done or produced, including new ways of working. Technology adoption refers to the stage at which the individual or the organisation selects technology for use, whereas diffusion refers the stage in which technology spreads to general use and application (Carr 2012). The success of ICT adoption is therefore generally measured by the degree of diffusion of the product within the organisation.

ICT adoption can be viewed from the activity lens as a dual sense of practice in social theory: firstly as something that is used to guide activity and secondly as the activity itself. Accordingly, 'practices' of ICT adoption refers to shared activities and behaviours including the traditional norms, methods and procedures for sense-making in selecting the technology of choice for adoption. The more these norms become embedded within the organisation, the greater the opportunity for these norms to become practices that shape practitioner's behaviour in accomplishing the day-to-day activities. This practice may be evident when preference is always given to internally established technologies to leverage off existing investments unless the organisation intends to capitalise on emerging technologies by pursuing strategic advantage (Khanagha et al. 2013:53). The rationale for this behaviour is that the adoption of new technology can radically affect organisations' operations, especially if the adopted technology is different from the internally established core technologies (Khanagha et al. 2013:52).

It is crucial that management has an understanding of the factors that can influence the adoption of new technologies (Sultan \& Chan 2000:106), as not every technology innovation will be of strategic importance. Decision-making for ICT 
adoption by management is influenced by both the rate and the speed of adoption. The rate of adoption relates to the need to introduce innovativeness into the organisation. An organisation with a high adoption rate indicates a higher drive for innovation towards efficiency or competitive advantage. The speed of adoption relates to the timing of when the innovation was introduced into the market. Organisations may adopt a wait-and-see approach to determine the success of the innovation. Management's approach to ICT adoption is early or delayed, depending on the organisational readiness and need. These aspects of organisational behaviour are usually dictated by the organisation's risk appetite when introducing something new to the organisation. This behaviour is usually influenced by the organisational culture, which ultimately stems from long-standing social practices within the organisation. Organisational culture influences organisational readiness and can contribute either positively or negatively towards the adoption of technology (Johnson 2010:161). Organisational readiness is also influenced by factors such as organisational policies, capital investments available for adoptive technologies and internal practices and procedures, activities that shape the day-to-day work of strategy-making.

\section{Strategy tools and their benefits}

Managers need to understand where in the technology life cycle a particular innovation is and what the potential strategic benefits will be before they decide to adopt the technology (Meade \& Rabelo 2004:669). The value this understanding brings to the work of managers is that it prevents managers participating in lengthy decisionmaking processes, only to adopt technology that becomes obsolete soon after the decision was taken, thereby rendering the adoption useless. ICT adoption tools assist managers in decision-making activities and aid in minimising uncertainties, thereby preventing poor decisions. The use of tools from the practice lens aid in performing strategy praxis, which is all about performing the actual work of strategymaking. Four pertinent models relating to ICT adoption assist managers in activities relating to ICT adoption. These models are diffusion of innovation, technology acceptance model, s-curve and technology adoption life cycle model.

The technology s-curve is a model that is frequently used by organisations to track the technological progress of an innovation. The model was so named because the plot of technological progress often takes an 's' shape. At the start, progress for any new technology is slow, then critical mass for the technology builds as expertise in the product increases. Eventually the technology matures and progress is again slow. This is followed by an ensuing decline of the product or the start of an new innovation (Asthana 1995:49).

The technology adoption life cycle model describes the adoption or acceptance of a new product or innovation. Originally developed by Everett Rogers, this model classifies adopters of innovations into various categories, namely innovators, early adopters, early majority, late majority or laggards. Meade and Rabelo (2004:668) later modified this model to indicate the chasm that exists between the early adopters and the early majority.

In addition to these models that track the progress of technology, numerous authors have attempted to define pertinent aspects of ICT adoption. However, most authors have expanded their technology innovation and adoption models on the seminal works of Rogers (1995), diffusion of innovation (DOI) and Davis's (1989) Technology Acceptance Model (TAM), which forms the basis of the study's ICT adoption framework. Venkatesh and Davis (2000) expanded the TAM model to include 'subject norms' to determine the changes they bring with increased user experience of the target system over time. This is referred to as the TAM2 model. The DOI model posits that the adoption of innovation occurs in stages and that the adopters' decision to adopt the technology is based on their perceptions of the technology. The TAM and TAM2 models focus on adopters' behaviours and posit that their beliefs affect their attitude for the technology that, in turn, influences their intentions and usage of the technology. Table 3 contains the critical ICT adoption factors and lists their characteristics. These models provide the formal analysis in the practitioner's search for rationality and logic by minimising uncertainties in ICT adoption decisionmaking activities.

\section{Drivers of information and communications technology adoption}

Decision-makers in key leadership positions are well aware that in today's contemporary environment, it is technology that is the driving change and that change demands technology (Barba-Sanchez, Martinez-Ruiz \& JimenezZarco 2007). Frambach and Schillewaert (2002:165) and Tarafdar and Vaidya (2006:428) assert that the degree to which an organisation is responsive to new technology will influence its tendency to adopt new technology. According to Sieber and Valor (2008:3), the main driving force behind technology adoption is no longer dependent on just the 'cost-saving' criteria or the 'automation' of tedious tasks but rather on the strategic implication it offers. In a study done by Harindranath, Dyerson and Barnes (2008:92), the leading strategic advantage of ICT adoption was 'keeping abreast of competitors' and benefits in operational efficiencies.

Technology adoptions are a combination of 'push' and 'pull' influences. Thong (1999:190) suggests that technology innovations can occur as a result of 'technology-push' or 'market-pull'. In 'market-pull', he postulates that a social need is felt, which gives rise to a technical demand. In 'technologypush' he asserts that a new technology is produced from an opportunity in the market, which compels the market to absorb the innovation. Both 'technology-push' and 'marketpull' influence technology adoption. According to Gartner 
(2008:14), the 'push' approach to innovation is expedient when an organisation wants to 'lead with technology' as opposed to the 'pull' approach which is business-led. Drivers can be viewed as a 'resource', 'process' or 'condition' that are essential for the sustained success and development of the organisation. Critical drivers are the key motives or the main force behind the need for decision-makers to adopt technology. These positive factors provide decisionmakers with the impetus to adopt technology. From practice perspective, ICT adoption drivers provide the discourse that precedes the decision-making activities of ICT adoption decisions. These drivers shape the strategy decisions and inform strategy objectives.

\section{Barriers to information and communications technology adoption}

As much as the adoption of technology promises to bring value with strategic benefits to an organisation, past failures in competitive organisations tend to make decisionmakers risk averse to the adoption of the very technology that promises strategic advantages. The most important challenges of adopting technology are associated with human factors. According to Russel and Hoag (2004:103), the implementation of technology adoption has mostly failed because of issues associated with user awareness, project management and the organisation's culture. Corrocher and Fontana (2008:231) state that organisations may view barriers to technology differently depending on individual characteristics, organisational function and market features, which may strongly influence adopters' behaviour. Barriers serve as inhibiting factors that either prevent or delay decision-makers from adopting technology released in their environment. Barriers have a tendency to become more permanent practices that are often seen as predisposing negative patterns of strategising activities. This may largely be as a result of conservative behaviours by practitioners in taking risky decisions that previously proved costly.

\section{Research methodology}

Literature was analysed using principles of grounded theory for articles reporting on strategy-making that concentrated on key constructs of strategy, management and ICT adoption, with the intention of understanding ICT adoption in the 'modern' business context. Research on ICT adoption studies were critically analysed to identify the factors that influence ICT adoption and to understand how these factors influence activities of ICT adoption. The inventory of the articles examined is presented in Table 2. Table 1 highlights the design components used in this article.

\section{Research process}

The principal aim of this article was to identify ICT adoption factors and improve the general understanding of the challenges that ICT adoption presents to organisations in the modern business context. The reason for this 'thin description' is to guide future focus areas for in-depth research and development. The eventual proposed framework depends on the identification of the correct elements.

Academic sources and databases were searched with key words including strategising for ICT adoption, ICT adoption, Rogers diffusion theory, Davis adoption theory, strategy-as-practice disruptive technologies, emerging technologies, drivers and barriers to ICT adoption, factors influencing ICT adoption, strategy-making, technology adoption, management and ICT adoption and ICT adoption factors and innovation challenges. Each article was screened for relevance to determine if it contributed to ICT adoption, adoption factors or drivers and barriers to ICT adoption. If it contributed, it was analysed further for relevant subject matter and included in the tabularised findings. Factor characteristics influencing ICT adoption were extracted, rationalised and classified against the three critical ICT adoption categories. When a 'seminal' article was identified, its reference for potential contributing articles was further explored.

The principles of grounded theory were adopted (Corbin \& Strauss 1990; Saunders, Lewis \& Thornhill 2009:149) such that the repetitive reading of the selected articles led the researchers to identify principal categories typically

TABLE 1: This article's research design components.

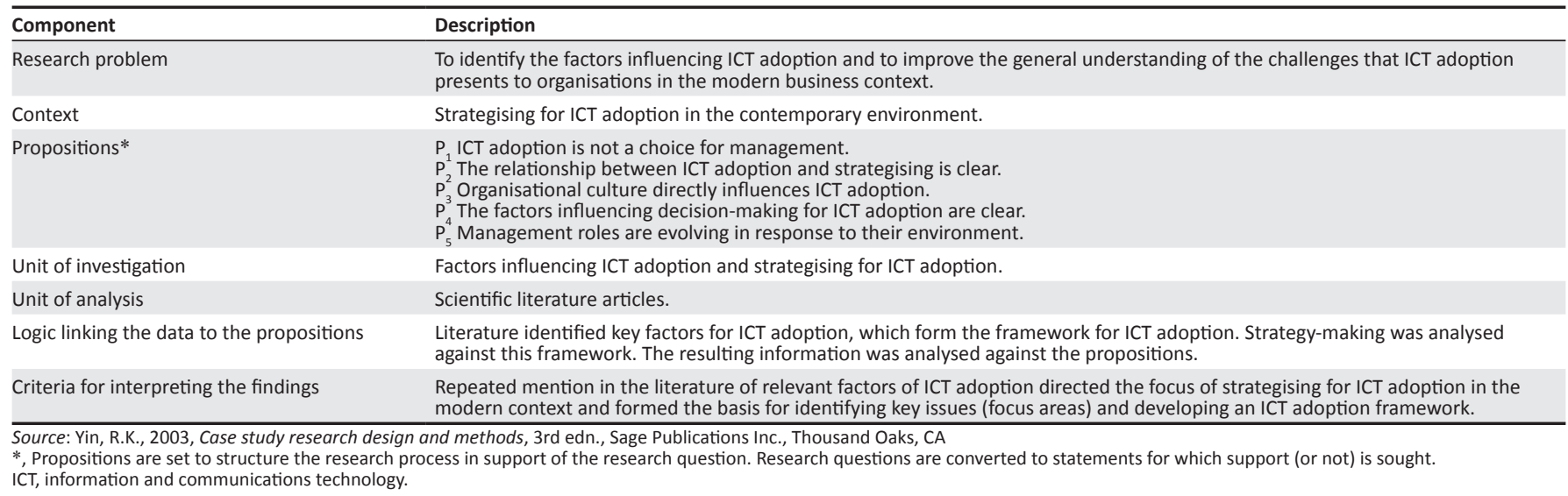


TABLE 2: Literature studies on ICT adoption.

\begin{tabular}{|c|c|c|c|}
\hline Phenomenon investigated or unit of investigation & Participation in strategising & Type of study & Author(s) and year \\
\hline \multicolumn{4}{|l|}{ Generic study focus: Strategy, Strategising, Management } \\
\hline $\begin{array}{l}\text { Moderating influence on the relationship between user perception } \\
\text { about ICT innovation and adoption decisions. }\end{array}$ & Both & Field & Agarwal \& Prasad 1998 \\
\hline UK retailers' adoption of electronic data interchange. & Both & Empirical & Bamfield 1994 \\
\hline Model for organisational structure - innovation relationships. & Both & Literature & Damanpour \& Gopalakrishnan 1998 \\
\hline ICT adoption factors in Australian small and medium enterprises (SMEs). & Top down & Empirical & Fink 1998 \\
\hline ICT adoption within SMEs. & Both & Literature & Ghobakhloo et al. 2012 \\
\hline ICT adoption in UK SMEs. & Top down & Empirical & Harindranath et al. 2008 \\
\hline Factors of adoption and usage in industrial e-markets. & Both & Case & Johnson 2010 \\
\hline Antecedent drivers of Internet technology adoption in small business. & Top down & Field & Lee 2004 \\
\hline Factors impacting the adoption of new technology in Brazil. & Both & Case & Nemoto, De Vasconcellos \& Nelson 2010 \\
\hline Strategic importance of e-commerce adoption. & Top down & Literature & Pires \& Aisbett 2003 \\
\hline Business factors that influence ICT adoption in banks in Thailand. & Both & Empirical & Ratanapoophun \& Lee 2010 \\
\hline Management praxis of ICT adoption in SMEs. & Both & Case & Ritchie \& Brindley 2005 \\
\hline ICT adoption criteria used by Spanish companies. & Both & Empirical & Sieber \& Valor 2008 \\
\hline $\begin{array}{l}\text { Dynamic relationships between ICT adoption and management efforts } \\
\text { towards modernisation. }\end{array}$ & Both & Empirical & Spanos et al. 2002 \\
\hline $\begin{array}{l}\text { Resource-based view, new technology adoption attributed to sense and } \\
\text { response by firms' capabilities. }\end{array}$ & Top down & Field, Empirical & Srinivasan, Lilien \& Rangaswamy 2002 \\
\hline Individual focus on adoption of new technologies within organisations. & Both & Case & Sultan \& Chan 2000 \\
\hline ICT adoption factors in small business. & Top down & Literature & Thong 1999 \\
\hline Adoption factors of XBRL into an Australian company. & Both & Case & Troshani \& Doolin 2005 \\
\hline $\begin{array}{l}\text { Innovation characteristics and implementation processes in the } \\
\text { implementation context. }\end{array}$ & Both & Case & Yetton, Sharma \& Southon 1999 \\
\hline \multicolumn{4}{|l|}{ Generic study focus: Strategy, Strategising } \\
\hline Drivers for ICT adoption in Nigerian SMEs. & Both & Case & Apulu \& Latham 2011 \\
\hline User concern and role of demographics in ICT adoption. & Both & Case & Harris et al. 2004 \\
\hline Factors influencing adoption of technology in agriculture. & Top down & Case & Rubas 2004 \\
\hline \multicolumn{4}{|l|}{ Generic study focus: Strategy, Management } \\
\hline E-business adoption factors in smaller firms. & Top down & Literature & Fillis., Johannson \& Wagner 2004 \\
\hline $\begin{array}{l}\text { Organisational structure and decision-making procedures in the adoption of } \\
\text { innovation. }\end{array}$ & Top down & Case & Cohn \& Turyn 1984 \\
\hline Interaction of managerial tasks with ICT and its effect on ICT adoption. & Both & Empirical & Cooper \& Zmud 1990 \\
\hline $\begin{array}{l}\text { Influence of ICT adoption factors on local area network technologies on IT } \\
\text { managers of SMEs in Italy. }\end{array}$ & Top down & Case & Corrocher \& Fontana 2008 \\
\hline $\begin{array}{l}\text { Organisation and intra-organisation adoption decisions in marketing and } \\
\text { management. }\end{array}$ & Bottom up & Literature & Frambach \& Schillewaert 2002 \\
\hline Timing and intensity factors of Swiss firms' decision to adopt ICT. & Both & Empirical & Hollenstein 2004 \\
\hline $\begin{array}{l}\text { ICT adoption rate and implementation challenges in supply chain } \\
\text { management. }\end{array}$ & Top down & Case & Russel \& Hoag 2004 \\
\hline Organisational factors in e-commerce adoption in India. & Top down & Empirical & Tarafdar \& Vaidya 2006 \\
\hline Internet adoption by business in Singapore. & Top down & Empirical & Teo, Tan \& Buk 1998 \\
\hline \multicolumn{4}{|l|}{ Generic study focus: Strategy } \\
\hline Strategy-making in high-tech firms. & Top down & Case & Meade \& Rabelo 2004 \\
\hline \multicolumn{4}{|l|}{ Generic study focus: Strategising } \\
\hline IT adoption and job satisfaction in Jordanian firms. & Bottom up & Empirical & Attar \& Sweis 2010 \\
\hline ICT adoption in SMEs. & Bottom up & Literature & Barba-Sanchez et al. 2007 \\
\hline Impact of ICT skill constraints on ICT adoption and utilisation. & Both & Empirical & Forth \& Mason 2004 \\
\hline Decision-making factors to adopt new technology. & Both & Empirical & Gilbert, Balestrini \& Littleboy 2004 \\
\hline Factors impacting the adoption of new technology. & Both & Literature & Hall \& Khan 2003 \\
\hline Internet users' adoption of the Web for retail usage. & Both & Empirical & O’Cass \& Fenech 2003 \\
\hline Characteristics of innovation and adoption factors. & Both & Empirical & Teng, Grover \& Guttler 2002 \\
\hline
\end{tabular}

UK, United Kingdom; ICT, information and communications technology; SMEs, small and medium enterprises.

associated with drivers or barriers of ICT adoption and more. As the researchers' understanding developed and when additional articles did not contribute any more to new knowledge, it was decided that saturation was achieved. A list of all articles that were analysed, found to be useful and used in the establishment of the ICT adoption framework is presented in Table 2.

\section{Article contextualisation}

The research question identified in this article is part of a larger study concerning ICT adoption. Due to space limitations, this article reports only on the theory of strategising for ICT adoption in the 'modern' context, the organisational implications thereof and on the identification of ICT adoption factors with the intention 
TABLE 3: Characteristics of factors related to ICT adoption.

\begin{tabular}{|c|c|}
\hline Characteristics & Description \\
\hline \multicolumn{2}{|l|}{ Innovation factors } \\
\hline Relative advantage & $\begin{array}{l}\text { 'Degree to which an innovation is perceived as being better than the idea it supersedes'. The extent to which a potential adopter } \\
\text { views the innovations as offering an improvement over former ways of accomplishing the same tasks. }\end{array}$ \\
\hline Compatibility & $\begin{array}{l}\text { 'Degree to which an innovation is perceived to be consistent with the existing values, past experiences and needs of potential } \\
\text { adopters. Organisations have a tendency to avoid technologies that are incompatible with the already established internal technical } \\
\text { landscape. }\end{array}$ \\
\hline Complexity & 'Degree to which an innovation is perceived as difficult to use'. \\
\hline Observability & $\begin{array}{l}\text { 'Degree to which the results of an innovation are visible to others'. The extent to which its performance and related benefits are } \\
\text { evident and the results demonstrable to those adopting the technology. }\end{array}$ \\
\hline Operational effectiveness & $\begin{array}{l}\text { 'Perceived usefulness' of the technology. Possible increase in individuals' job performance and contribution towards overall } \\
\text { improved outputs. }\end{array}$ \\
\hline Systems openness & $\begin{array}{l}\text { Compatibility of the technology features with other technology across diverse platforms and the ability to integrate with other } \\
\text { complementary technologies. }\end{array}$ \\
\hline Resource intensiveness & $\begin{array}{l}\text { Peripheral technologies that are essential to derive the maximum value from the adopted technology. This may extend to the } \\
\text { hardware configuration, network topology and general system level characteristics such as security, reliability and scalability. }\end{array}$ \\
\hline \multicolumn{2}{|l|}{ External factors } \\
\hline Product life cycle and market conditions & $\begin{array}{l}\text { Technologies that have achieved critical mass may be avoided as they are likely to be in the mature stage. Little added value can } \\
\text { be achieved and this is likely to trigger new innovation. Technologies experiencing constant innovation may be avoided due to } \\
\text { technology obsolescence occurring more frequently. Rapid changes and advancement in technology give rise to uncertainty in the } \\
\text { industry. }\end{array}$ \\
\hline Competitive advantage and pressure & $\begin{array}{l}\text { The need to stay competitive and innovative as a means of survival to outperform competitors and the ability to create competitive } \\
\text { advantage. }\end{array}$ \\
\hline Global interdependencies & $\begin{array}{l}\text { Is the technology able to provide faster communication, closer coordination across firms' boundaries and cater for highly } \\
\text { decentralised networks? }\end{array}$ \\
\hline Interconnectedness & $\begin{array}{l}\text { Value of the technology grows with the total number of users who adopt it, for example social media. When there is critical mass of } \\
\text { users then the technology has a tendency to influence the adoption of associated innovations. }\end{array}$ \\
\hline Legislative & Government policies and initiatives in the form of financial aid and technical expertise increase the adoption of ICT. \\
\hline Unsuccessful adoptions & Implementations plagued with failures regarding technologies will breed contempt for the adoption of such technologies. \\
\hline \multicolumn{2}{|l|}{ Organisational factors } \\
\hline Culture & $\begin{array}{l}\text { Constructs of organisational culture, such as perceived norms, values and attitudes can affect the behaviour of employees towards } \\
\text { the adoption of ICT. }\end{array}$ \\
\hline Degree of risk-taking & $\begin{array}{l}\text { Uncertainty or riskiness associated with the technology versus the organisations' risk appetite. It is natural for organisations to avoid } \\
\text { obvious risks, which may lead them to ignore technologies that do not meet the required standards. However, certain technologies } \\
\text { may create potential competitive advantage, which may encourage organisations to adopt them despite the high levels of risk } \\
\text { associated with them. }\end{array}$ \\
\hline Top management support and attitude & $\begin{array}{l}\text { Studies indicate that success associated with technology adoption is directly linked to top management's positive support and } \\
\text { attitude towards the technology. }\end{array}$ \\
\hline Resources & $\begin{array}{l}\text { Technical and managerial resources available to support the adoption of the technology. An already established internal resource } \\
\text { base may positively influence the adoption of technology. }\end{array}$ \\
\hline Size and type & $\begin{array}{l}\text { Size of the organisation as defined by its turnover and the number of employees are important determinants. Larger firms usually } \\
\text { have bigger investment budgets, which may encourage them to adopt new technology sooner. The type of organisation also dictates } \\
\text { the level of ICT adoption. }\end{array}$ \\
\hline Maturity & $\begin{array}{l}\text { Business maturity in terms of the employee mindset towards technology adoption and the level of employee knowledge. A high } \\
\text { requirement for technology and technology savvy users will prefer adopting technologies that are more sophisticated. }\end{array}$ \\
\hline End user behaviour & $\begin{array}{l}\text { Characteristics of ICT users, such as their knowledge of ICT, their attitude and intention towards ICT, their exposure in the use of ICT } \\
\text { and their industry awareness, could influence their attitude and acceptance towards the adoption of the technology. }\end{array}$ \\
\hline Information intensity & $\begin{array}{l}\text { Organisations that rely on volumes of information either for their daily operations or for decision-making express a greater } \\
\text { propensity to adopt ICT. }\end{array}$ \\
\hline Policies & $\begin{array}{l}\text { Organisation's policies that are flexible for the adoption indicate that ICT decision-makers are aware of technology innovations and } \\
\text { are forward-looking in their strategic objectives. }\end{array}$ \\
\hline Interconnectedness & $\begin{array}{l}\text { Systems integration with internal technology and the value derived from the adoption of new technology, which can leverage off } \\
\text { existing infrastructure. Preference is given to technologies that are not tightly coupled for easy integration. }\end{array}$ \\
\hline Strategic objectives & $\begin{array}{l}\text { Strategic objectives and position of the organisation in relation to its competitors. Organisations that pursue an aggressive, } \\
\text { innovative market strategy are more likely to pursue the adoption of new technologies more regularly. }\end{array}$ \\
\hline ICT awareness & $\begin{array}{l}\text { Innovations engender competitive advantage via practical benefits. However, a lack of cognisance for the technology is likely to fuel } \\
\text { concerns for adopting the technology. }\end{array}$ \\
\hline Uncertainty of business benefits & $\begin{array}{l}\text { Decision-makers decline to adopt technology that does not contribute to benefits related to operational matters for improved } \\
\text { productivity, efficiency and response time. }\end{array}$ \\
\hline
\end{tabular}

ICT, information and communications technology.

of developing an ICT adoption framework. The proposed framework should give structure to the scattered and fragmented literature and thereby support detailed analysis in future research.

\section{Findings}

It is important to note that the analysis of the ICT adoption studies reported in Table 2 is largely based on Rogers and Davis's seminal works or adapted versions thereof. The critical ICT adoption factors presented in Table 3 were constructed from these studies and are a collaborative process, which included analysing discussions for relevance, filtering for adoption factors that support literature theory and influences stemming from modern business context. However, no one study made use of the comprehensive list of ICT adoption factors presented in Table 3. 


\section{Information and communications technology adoption factors}

The ICT adoption factors listed in Table 3 are categorised into three key factors, namely innovation, external and organisational. These three factors were selected based on their common recurrence in literature articles on ICT adoption and as an appropriate construct name for the characteristics of the attributes associated with the factor. These factors can be seen as drivers or barriers to ICT adoption decisionmaking activities depending on the context of whether the practitioners decide to adopt the technology sooner or delay the adoption of technology.

\section{Innovation}

Innovation factors are product-related characteristics that contribute towards ICT adoption. According to Garcia and Calantone (2002:112), 'innovation is an iterative process initiated by the perception of a new market and/or new service opportunity for a technology-based invention which leads to development, production and marketing tasks striving for the commercial success of the invention'.

\section{External}

Tidd et al. (in Troshani \& Doolin 2005:4) assert that a critical factor for the successful adoption of technology includes the ability of the organisation to 'predict and respond' to changes in the industry. External factors refer to industry pressures from the environment that influence decision-makers' adoption choice regarding the technology.

\section{Organisational}

Organisational factors refer to internal aspects that set the tone for ICT adoption. The type and size of the organisation influence not only the strategies that practitioners develop for market efficiencies but also the day-to-day activities and the type of ICT innovation adopted given the value of the budget available.

\section{Discussion and interpretation of the findings}

An analysis of the above research articles on ICT adoption, as summarised in Table 2 and Table 3, leads to the development of the proposed framework contextualising the three ICT adoption factors with the current opportunities and uncertainties under which strategising for ICT adoption occurs, which is illustrated in Figure 1. The contextual framework of challenges in the modern business environment features the three adoption factors and displays the challenges and opportunities available to organisations in the context of each factor. The discussions of the findings presented in this article, as well as the propositions, proceed in accordance with Figure 1 as a guideline.

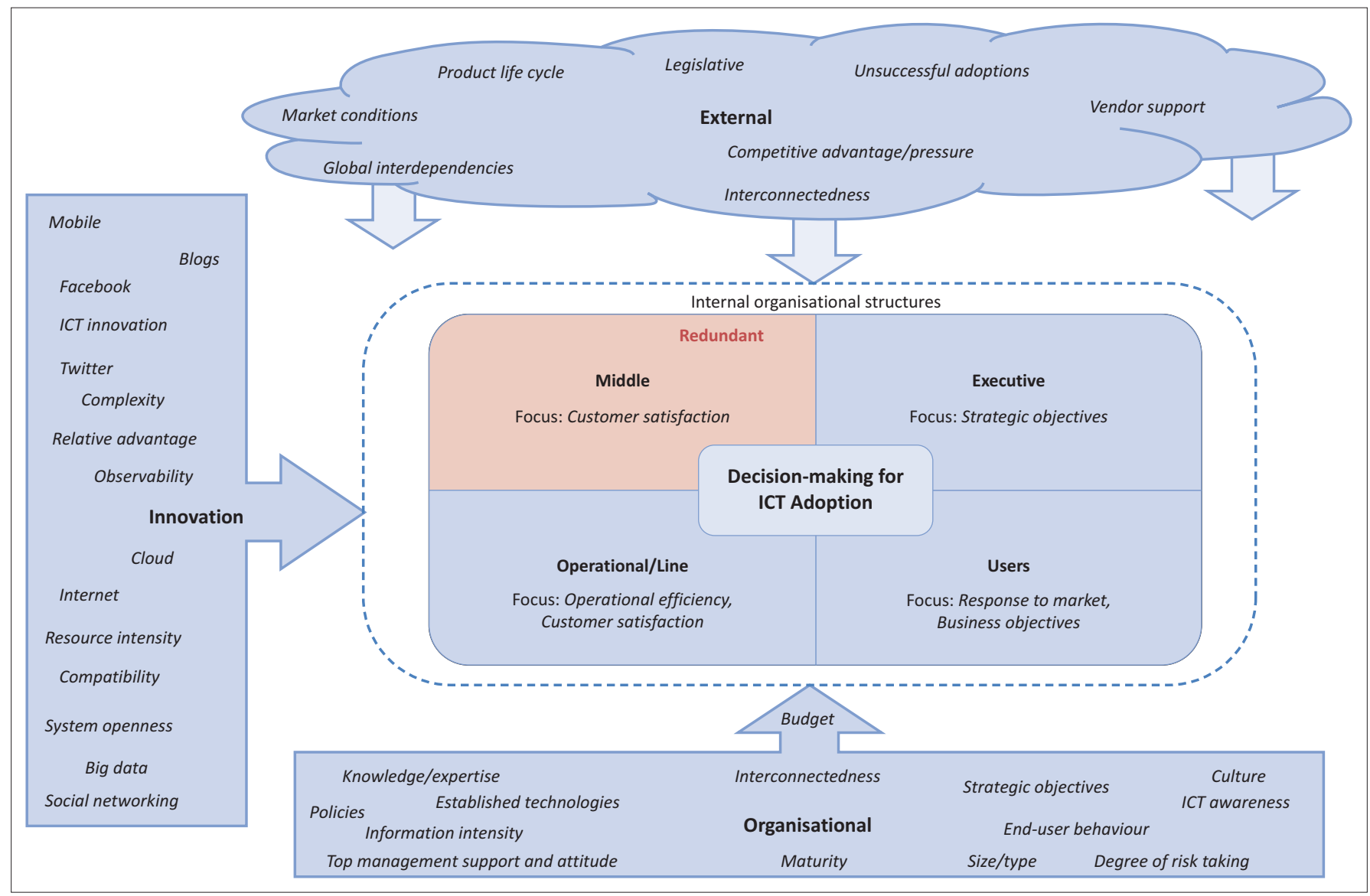

ICT, information and communications technology.

FIGURE 1: Framework of ICT adoption in the modern context. 
ICT advancements have followed the projection that Gordon Moore made in 1965 and are evolving more swiftly than ever before. The general trend of ICT is towards being smaller, cheaper, more powerful and more integrated into the daily operations of both individuals and organisations. Technology continues to overwhelmingly influence the manner in which organisations work, collaborate, communicate, interact, learn, socialise and eventually operate in almost every aspect of their dealings.

In line with the escalating pressures experienced in the external environments, there exists a growing demand on managers to improve operational, tactical and strategic processes. As an ostensible choice, managers are relying on ICT adoption as a means to this end (Cooper \& Zmud 1990:123). In order for organisations to exploit the strategic benefit of ICT adoption, they should preferably align their ICT strategy with their business strategies. However, with the rapid pace of technology advancement, it is becoming difficult to keep abreast of the latest trends to align these strategies sufficiently.

Over the past decade, technology has changed the modus operandi of organisations. The speed of technology innovations, coupled with increasing hyperconnectivity, has contributed towards environmental instability (Walsh, Kirchhoff \& Newbert 2002:342). Thus, the traditional models adopted by organisations to develop strategies and conduct business operations have become ineffective to sufficiently and timeously respond to market stimuli that affect strategic objectives. Extant research also indicates that the required approach to strategy formulation is one that can deal with the current environmental instability, whilst being agile and flexible to respond to the adaptive business needs. The greater the complexity facing organisations, the more difficult it becomes to develop appropriate strategies. Thus if complexity becomes too extensive then organisation actions become paralysed (Seidl 2003:3). Complexity needs to be minimised to achieve workable actions. S-as-p contributes towards this simplification by focusing on the micro activities of strategising thereby providing insight into the work and practices of practitioners, which shape strategy-making.

Technology adoption serves as a vehicle that allows management to participate in a world of constant innovation. At the same time, it serves as a catalyst for fundamental changes within the organisation. However, the right technology needs to be adopted in order for organisations to reap the benefits of technological innovations. The opportunity that technology adoption presents to managers is to understand the interdependence that exists between business strategies, business rules, processes and procedures and to determine how business can benefit from technology adoption. In capitalising on the s-as-p approach, managers can benefit greatly from its building blocks in unpacking the day-to-day micro activities that contribute towards strategy.
Used applicably, ICT adoption can enable management to close strategic gaps that may exist between the organisation and its environment. Strategising for ICT adoption can be seen as the activity of choosing technology by selectively incorporating the organisation's practices and contextual influences and, with the use of specialised tools, help make sound decisions. Although various tools can assist managers in determining the phase of a particular technology to better understand the technology's potential value, technology adoption is dependent on many other factors, as indicated by the adoption framework that is presented in this article. The use of ICT is critical to the economic survival and bottom line of organisations. Failing to participate in technology adoption creates the risk of organisations being negatively marginalised (Spanos et al. 2002:659). Although technology is important in shaping strategic outcomes, extant literature is not prescriptive on what technology to adopt. This remains the prerogative of organisations as governed by the relevant adoption factors. Therefore, there is partial support for proposition 1, which states that ICT adoption is not a choice for management.

Given the dynamic forces at play in the market environment, managers cannot afford to delay decision-making by having complicated decision structures. Customers and clients alike expect fast turnaround times for service delivery. Hierarchical structures by their very nature imply longer turnaround times for decision-making. It is evident that with increased uncertainty and environmental challenges experienced through technological innovations and technology adoption, the approach to strategising is changing (Barkema, Baum \& Mannix 2002:916; Hart \& Banbury 1994:266). This occurs predominantly because of management's response to innovations in technology. In the current economy, strategists will not always develop strategies behind closed doors or in secret meetings. In a study undertaken by Dameron and Torset (2009) on the strategists' discourse on their practices, it was found that strategists rely on 'social interactions, complementary collaborations, intuition and action' to develop their strategies. Due to the contextual difference in organisations, insufficient support was found for proposition 2, which states that understanding the relationship between ICT adoption and strategising is clear.

The interplay that exists in an organisation amongst the various actors sets the culture for the organisation, which inadvertently governs its structures, policies, practices and strategising activities that shape strategy. Preference is always given to internally established technologies to leverage off existing investments, unless the organisation intends to capitalise on emerging technologies by pursuing strategic advantage (Khanagha et al. 2013:53). Organisational culture influences organisational readiness and can contribute either positively or negatively towards the adoption of technology (Johnson 2010:161). Management's approach and response to the speed of adoption is either early or delayed, depending on the organisational readiness and need. There seems to be sufficient support in literature to support proposition 3, 
that organisational culture directly influences ICT adoption, and for proposition 4, that the factors influencing decisionmaking for ICT adoption are clear. Despite the above, how these factors influence decision-making warrants further investigation. Evidence of the factors influencing ICT adoption decisions is provided in the form of the ICT adoption framework, which was the outcome of this study. This is presented in Table 3 in this article.

Technology adoption, especially where major ICT innovation is concerned, is not only pervasive but also influences many aspects of organisational activity (Pires \& Aisbett 2003:293). This trend is guaranteed to continue with the advancement in technology. In addition to the advocacy needed to ensure the conditions necessary for technological adoption, managers must compete with other organisational priorities. As technology advances, so too must the organisation to ensure its strategic survival. The critical challenge facing management is to address these changes adequately. An organisation's structures and management's roles must evolve to be flexible and agile to respond to the external environment. From the literature evidence, it is clear that organisations have no choice but to adjust accordingly. This is evident from the demise of those brick and mortar organisations that refused to adapt their strategies to that of the changing environment with the advent of the Internet. Thus, proposition 5 is supported in that management's roles are evolving in response to the organisation's changing environment. However further research is necessary to provide greater understanding on the impact this has on organisational structures.

\section{Analysis of factors from an s-as-p view}

ICT adoption can be viewed through the activity lens as a dual sense of practice in social theory: firstly as something that is used to guide activity and secondly as the activity itself. In the context of 'guiding activity', ICT adoption relates to associated practices involved in decision-making and shaping managerial views on ICT adoption. In terms of the 'activity itself', ICT adoption is associated with actions taken to accomplish the actual work of ICT adoption for example setting up of workshops, drawing up of budget, making presentations on ICT adoption and the like.

Using the practice lens the innovation factor is largely characterised by thinking and logical sense-making stemming from the practitioners perception of the technology being adopted. The rationale for this view may be a result of the practitioner's praxis, which looks to technology as a means of improving their day-to-day activities. This expectation becomes ingrained into the fabric of the aggregate actor's paradigm and as a result over time may become established in organisational policies and decision-making. Ultimately, the outcome of this has the potential to shape strategising activities for ICT adoption. The drawback of this social thinking is that sometimes perceptions may be wrong and the result is poor performance or costly decisions.
External factors are largely a result of market influences that shape the behaviour of organisational work and that become embedded into everyday activities. Knowledge about specific types of technology, industry successes and failures relating to a technology and reputational view about a technology contributes to establishing patterns relating to technology products. This pattern over time becomes practice that practitioners look to for guidance, which influences strategising for ICT adoption. However, differentiation and change in the use of technology become critical to achieve competitive advantage; recursive practices then present a challenge to strategic management if practitioners are largely reliant on past practices. Thus, it becomes imperative that social practices embedded in organisations need to evolve and have adaptive characteristics that can appropriately influence ICT adoption.

In the context of a practitioner's work, activities may become localised to specific individuals who are responsible for filtering information to decision-makers. In technologycentric industries these individuals maybe specialists who may not occupy executive positions but still have the ability to shape strategy. Although an organisation's culture may to a large extent drive individual behaviours in work practices, sub-cultures amongst the user community are prone to like-minded thinking that can influence activities in decision-making for ICT adoption.

\section{Conclusion}

The intention of this article was to analyse existing literature on ICT adoption with the intention of developing an ICT adoption framework and to strengthen the understanding of strategising in the context of ICT adoption. In doing so, the study revealed that formulating appropriate strategies is more important now than ever before. However, given the uncertainty that exists in the current environment, market opportunities and risks have transformed the manner in which strategies are formulated (Courtney 2001:38). It is necessary for strategies to be much more flexible and adaptable to cater for the changing nature of and uncertainties experienced in the external environment, as this ensures long-term organisational sustainability. It is clear from the research that a more agile approach to strategy formulation is required. New approaches to strategy-making are necessary to reduce the complexity involved in strategy decisions. An s-as-p perspective helps to reduce the complexity involved in strategy-making by focusing on the micro activities of strategising. S-as-p provides invaluable insight into the understanding of strategic management, managerial activities and decision-making. In unveiling the micro activities involved in strategising, a better understanding is achieved on how organisations deal with the day-to-day uncertainties of the contemporary environment.

Advancements in ICT innovations contribute towards the strategic challenges that managers have to endure on a daily basis and have a significant impact on management's approach to strategising. Used appropriately, technology 
adoption can enable management to close strategic gaps that may exist between the organisation and its environment. In the context of technology adoption, strategising for ICT adoption can be seen as the activity of choosing appropriate technology by selectively incorporating the organisation's practices and contextual influences into decision-making activities that culminate in the adoption of technology. This article successfully compiled a comprehensive list of ICT adoption factors that can assist practitioners in informing decision-making activities for ICT adoption. It provided detailed characteristics of each factor and provided contextual understanding of how these factors can influence the manner in which practitioners view ICT adoption. ICT adoption factors can be further categorised into drivers and barriers that have the potential to predispose decision-making and hence shape strategising activities. In addition, it considered the drawbacks of past practices influencing decision-making activities in the modern context of strategy-making.

\section{Management implications}

This article contributes to an increased understanding and visibility of disruptions caused by ICT innovations and the adoption thereof. It also highlights the importance for organisations to align themselves with their environment and to successfully leverage off the benefits provided through ICT adoption. In emphasising the challenges presented by ICT innovation and the need for organisations to better align themselves with their environment, organisations can proactively relook at internal organisational structures and activities to get ahead of the disruptive ICT curve. This article provides a comprehensive list of factors that influence ICT adoption. ICT adoption clearly provides a means for organisations to realise their strategic objectives, but it is not without risks and challenges if adopted inappropriately.

\section{Limitations and suggestions for future research}

Although this article attempts to highlight the critical aspects of ICT adoption by synthesising extant literature on the topic, there are some limitations of the article. ICT adoption factors have been based largely on the seminal works of Roger and Davis. New research is required to factor in the disruptive influence of radical ICT innovations and the adoption influence on user behaviour to determine the contemporary relevance of these adoption models. Extant literature is very expansive on aligning business and ICT strategies. However, this implies that ICT plays a supportive role in business. Whereas this may be true in some instances, it is evident from literature that ICT plays more of a strategic role in the modern business context. This is quite evident from the manner in which ICT is shaping business outcomes through social media, big data, mobile technology and cloud computing. In addition, it is clear from the research that management roles are blurring but the extent to which this influences new organisational structures needs to be explored further. A gap exists in the literature in that empirical research needs to be conducted to determine the contemporary contribution of ICT adoption to an organisation's strategic versus operational benefit. Empirical research needs to be conducted to determine the relevance of adoption factors listed in this study in the contemporary context. Further research needs to be conducted to understand how the activities of ICT adoption are performed and by whom.

\section{Acknowledgements Competing interests}

The authors declare that they have no financial or personal relationship(s) which may have inappropriately influenced them in writing this article.

\section{Authors' contributions}

Both authors (University of Pretoria) contributed to the writing and research of this article.

\section{References}

Adner, R., 2004, 'A demand based perspective on technology life cycles', Advances in Strategic Management 21, 25-43. http://dx.doi.org/10.1016/S07423322(04)21001-4

Agarwal, R. \& Prasad, J., 1998, 'The antecedents and consequents of user perceptions in information technology adoption', Decision Support Systems 22, 15-29. http:// dx.doi.org/10.1016/S0167-9236(97)00006-7

Andersen, T.J., 2001, 'Information technology, strategic decision making approaches and organisational performance in different industrial settings', Journal of Strategic Information Systems 10, 101-119. http://dx.doi.org/10.1016/S09638687(01)00043-9

Apulu, I. \& Latham, A., 2011, 'Drivers for information and communication technology adoption: a case study of Nigerian small and medium sized enterprises', International Journal of Business and Management 6(5), 51-60. http://dx.doi. org/10.5539/ijbm.v6n5p51

Asthana, P., 1995, 'Jumping the technology s-curve', IEEE Spectrum June, 49-54. http://dx.doi.org/10.1109/6.387142

Attar, G.A. \& Sweis, R.J., 2010, 'The relationship between information technology adoption and job satisfaction in contracting companies in Jordan', Journal of Information Technology in Construction 15, 44-63.

Bakos, J.Y. \& Treacy, M.E., 1986, 'Information technology and corporate strategy: A research perspective', MIS Quarterly 10(2), 107-119. http://dx.doi. org/10.2307/249029

Bamfield, J., 1994, 'Technological Management Learning the adoption of electronic data interchange by retailers', International Journal of Retail Distribution Management 22(2), 3-11. http://dx.doi.org/10.1108/09590559410054077

Barba-Sanchez, V., Martinez-Ruiz, M.D.P. \& Jimenez-Zarco, A.I., 2007, 'Drivers, benefits and challenges of ICT adoption by small and medium sized enterprises', Problems and Perspectives in Management 5(1), 103-114.

Barkema, H.G., Baum, J.A.C. \& Mannix, E.A., 2002, 'Management challenges in the new time', The Academy of Management Journal 45(5), 916-930. http://dx.doi. org $/ 10.2307 / 3069322$

Bitar, J. \& Hafsi, T., 2007, 'Strategizing through the capability lens: Sources and outcomes of integration', Emerald Management Decision 45(3), 403-419. http:// dx.doi.org/10.1108/00251740710745043

Carr, V.H., 2012, United States air force centre for strategy and technology, viewed December 20, 2012, from http://www.au.af.mil/au/awc/awcgate/innovation/ adoptiondiffusion.htm

Chapman, J.A., 2001, 'The work of managers in new organisational contexts', The Journal of Management Development 20(1), 55-68. http://dx.doi. org/10.1108/02621710110364790

Chia, R. \& MacKay, B., 2007, 'Post-procedural challenges for the emerging strategyas-practice perspective: 'Discovering strategy in the logic of practice', Human Relations 60(1), 217-242. http://dx.doi.org/10.1177/0018726707075291

Christensen, C.M. \& Overdorf, M., 2000, 'Meeting the challenge of disruptive change', Harvard Business Review March-April, 1-11.

Cohn, S.F. \& Turyn, R.M., 1984, 'Organisational structure, decision-making procedures, and the adoption of innovations', IEEE Transactions on Engineering Management 31(4), 154-161. http://dx.doi.org/10.1109/TEM.1984.6447531

Cooper, R.B. \& Zmud, R.W., 1990, 'Information technology implementation research A technological diffusion approach', Management Science 36(2), 123-139. http:// dx.doi.org/10.1287/mnsc.36.2.123

Corbin, J. \& Strauss, A., 1990, 'Grounded theory research: Procedures, canons and evaluative criteria', Qualitative Sociology 13(1), 3-21. http://dx.doi.org/10.1007/ BF00988593 
Corrocher, N. \& Fontana, R., 2008, 'Objectives, obstacles, and drivers of ICT adoption: What do IT managers perceive', Information Economics and Policy 20(March) 229-242. http://dx.doi.org/10.1016/j.infoecopol.2008.03.001

Courtney, H., 2001, 'Making the most of uncertainty', The Mckinsey Quarterly 4, 38-47.

Damanpour, F. \& Gopalakrishnan, S., 1998, 'Theories of organisational structure and innovation adoption: The role of environment change', Journal of Engineering and Technology Management 15, 1-24. http://dx.doi.org/10.1016/S09234748(97)00029-5

Dameron, S. \& Torset, C., 2009, 'Strategists in an uncertain world: Practice and tools to face tensions', paper presented at the Strategic Management Society Annual Conference, Session 122, Washington, DC, October 2009.

Davis, F.D., 1989, 'Perceived usefulness, perceived ease of use, and user acceptance of information technology', MIS Quarterly 13(3), 319-340. http://dx.doi. org $/ 10.2307 / 249008$

Drucker, P.F., 1988, 'The coming of the new organisation', Harvard Business Review January-February, 3-11.

Dutta, S. \& Bilbao-Osorio, B., 2012, The global information technology report 2012, SRO-Kundig, Geneva Switzerland, viewed 06 November 2012, from http://www3. weforum.org/docs/Global_IT_Report_2012.pdf

Elter, F., 2004, Strategising in complex contexts, viewed 17 April, 2011, from http:// kunne.no/upload/Gamle publikasjoner/Konferansepaper/Strategizing in Complex Contexts_Elter_2004.pdf

Fillis, I., Johannson, U. \& Wagner, B., 2004, 'Factors impacting on e-business adoption and development in the smaller firm', International Journal of Entrepreneurial Behaviour and Research 10(3), 178-191. http://dx.do . org/10.1108/13552550410536762

Fink, D., 1998, 'Guidelines for the successful adoption of information technology in small and medium enterprises', International Journal of Information Managemen 18(4), 243-253. http://dx.doi.org/10.1016/S0268-4012(98)00013-9

Forth, J. \& Mason, G., 2004, 'Information and Communication Technology (ICT) adoption and utilisation, skill constraints and firm level performance: evidence from UK benchmarking surveys', paper presented at the National Institute of Economic and Social Research, Paper 234, London, UK, March 2004.

Frambach, R.T. \& Schillewaert, N., 2002, 'Organisational innovation adoption: A multi-level framework of determinants and opportunities for future research', Journal of Business Research 55, 163-176. http://dx.doi.org/10.1016/S0148 2963(00)00152-1

Friar, J. \& Horwitch, M., 1985, 'The emergence of technology strategy: A new dimension of strategic management', Technology in Society 7, 143-178. http:// dx.doi.org/10.1016/0160-791X(85)90023-5

Garcia, R. \& Calantone, R., 2002, 'A critical look at technological innovation typology and innovativeness terminology: A literature review', The Journal of Product Innovation Management 19(May), 110-132. http://dx.doi.org/10.1016/s07376782(01)00132-1

Gartner, 2008, Mastering the paradoxes of innovation 159181, viewed 18 March, 2012, from http://www.gartner.com

Ghobakhloo, M., Hong, T.S., Sabouri, M.S. \& Zulkifli, N., 2012, 'Strategies for successful information technology adoption in small and medium sized enterprises', Information 3(February), 36-67.

Gilbert, D., Balestrini, P. \& Littleboy, D., 2004, 'Barriers and benefits in the adoption of e-government', The International Journal of Public Sector Management 17(4), 286-301.

Goll, I., Johnson, N.B. \& Rasheed, A.A., 2007, 'Knowledge capability, strategic change, and firm performance', Management Decision 45(2), 161-179.

Golsorkhi, D., Rouleau, L., Seidl, D. \& Vaara, E., 2010, Cambridge handbook of strategy as practice, Cambridge University Press, Cambridge.

Hall, B.H. \& Khan, B., 2003, UC Berkeley Department of Economics, viewed 11 April, 2012, from http://escholarship.org/uc/item/3wg4p528

Harindranath, G., Dyerson, R. \& Barnes, D., 2008, 'ICT adoption and use in UK SMEs: A failure of initiatives?', Electronic Journal of Information Systems Evaluation 11(2) 91-96.

Harris, E., Stanz, K., Zaaiman, J. \& Groenewald, T., 2004, 'The stages of users' concern when adopting new technology', SA Journal of Human Resource Management 2(3), 54-61.

Hart, S. \& Banbury, C., 1994, 'How strategy-making processes can make a difference', Strategic Management Journal 15(4), 251-269.

Hendry, J., 2000, 'Strategic decision making, discourse, and strategy as social practice', Journal of Management Studies 37(7), 955-977.

Hollenstein, H., 2004, 'Determinants of the adoption of information and communication technology (ICT): An empirical analysis based on firm level data for the Swiss business sector', Structural Change and Economic Dynamics 15, 315-342.

Jarratt, D. \& Stiles, D., 2010, 'How are methodologies and tools framing managers' strategizing practice in competitive strategy development?', British Journal of Management 21, 38-43.

Jarzabkowski, P., 2003, 'Strategic practices: An activity theory perspective on continuity and change', Journal of Management Studies 40(1), 23-55.

Jarzabkowski, P., 2004, 'Strategy as practice: Recursive, adaptation and practices-in-use', Organisation Studies 25(4), 529-560. http://dx.doi. org/10.1177/0018726707075703

Jarzabkowski, P., Balogun, J. \& Seidl, D., 2007, 'Strategizing: The challenges of a practice perspective', Human Relations 60(1), 5-27. http://dx.doi.org/10.1111/ j.1468-2370.2008.00250.x
Jarzabkowski, P. \& Spee, A.P., 2009, 'Strategy-as-practice', International Journal of Management Reviews 11(1), 69-95. http://dx.doi.org/10.1111/1467-6486.00296

Jarzabkowski, P. \& Wilson, D.C., 2002, 'Top teams and strategy in a UK university', Journal of Management Studies 39(3), 355-381.

Johnson, M., 2010, 'Barriers to innovation adoption: A study of e-markets', Industrial Management and Data Systems 110(2), 157-174. http://dx.doi org/10.1108/02635571011020287

Kearns, G. \& Sabherwal, R., 2006, 'Strategic alignment between business and information technology: A knowledge-based view of behaviours, outcome and consequences', Journal of Management Information Systems 23(3), 129-162. http://dx.doi.org/10.2753/MIS0742-1222230306

Khanagha, S., Volberda, H., Sidhu, J. \& Oshri, I., 2013, 'Management innovation and adoption of emerging technologies: The case of cloud computing', European Management Review 10, 51-67. http://dx.doi.org/10.1111/emre.12004

Lee, J., 2004, 'Discriminant analysis of technology adoption behaviour: A case of internet technologies in small businesses', The Journal of Computer Information Systems 44(4), 57-66.

Mantere, S. \& Vaara, E., 2008, 'On the problem of participation in strategy: A critical discursive perspective', Organization Science 19(2), 341-358. http://dx.doi. org/10.1287/orsc.1070.0296

Meade, P.T. \& Rabelo, L., 2004, 'The technology adoption life cycle attractor: understanding the dynamics of high-tech markets', Technological Forecasting and Social Change 71, 667-684. http://dx.doi.org/10.1016/j.techfore.2004.01.008

Nemoto, M.C.M., De Vasconcellos, E.P.G. \& Nelson, N., 2010, 'The adoption of new technology: Conceptual model and application', Journal of Technology Management and Innovation 5(4), 95-107. http://dx.doi.org/10.4067/S071827242010000400008

O'Cass, A. \& Fenech, T., 2003, 'Web retailing adoption: Exploring the nature of internet users web retailing behaviour', Journal of Retailing and Consumer Services 10 81-94. http://dx.doi.org/10.1016/S0969-6989(02)00004-8

Pires, G.D. \& Aisbett, J., 2003, 'The relationship between technology adoption and strategy in business-to-business of e-commerce', Industrial Marketing Management 32, 291-300. http://dx.doi.org/10.1016/S0019-8501(02)00237-7

Ratanapoophun, S. \& Lee, S.M., 2010, The relationship between business factors affecting information and communication technology adoption in the Thai banking industry, viewed 10 April, 2012, from http://www.bu.ac.th/knowledgecenter/ epaper/july_dec2010/pdf/P_133-145.pdf

Ritchie, B. \& Brindley, C., 2005, 'ICT adoption by SMEs: Implications for relationships and management', New Technology, Work and Employment 20(3), 205-217. http://dx.doi.org/10.1111/j.1468-005x.2005.00154.x

Rogers, E.M., 1995, Diffusions of innovations, 4th edn., Free Press, New York.

Rubas, D., 2004, Technology adoption: Who is likely to adopt and how does the timing affect the benefits?, viewed 10 April, 2012, from http://repository. tamu.edu/bitstream/handle/1969.1/1252/etd-tamu-2004B-AGEC-Rubas-2. pdf?sequence $=1$

Russel, D.M. \& Hoag, A.M., 2004, 'People and information technology in the supply chain: Social and organisational influences on adoption', Internal Journal of Physical Distribution and Logistics Management 34(2), 102-122. http://dx.doi. org/10.1108/09600030410526914

Saunders, M., Lewis, P. \& Thornhill, A., 2009, Research methods for business students, Pearson Education Limited, Edinburgh Gate, Essex.

Seidl, D., 2003, The role of general strategy concepts in the practice of strategy viewed 03 March, 2013, from http://www.en.bwl.uni-muenchen.de/research/ diskus_beitraege/workingpaper/3375.doc.

Shiels, H., Mclvor, R. \& O'Reilly, D., 2003, 'Understanding the implications of ICT adoption: Insights from SMEs', Logistics Information Management 16(5), 312326. http://dx.doi.org/10.1108/09576050310499318

Sieber, S. \& Valor, J., 2008, Criteria for adopting information and communication technologies, Business and information technologies project: E-business Centre PricewaterhouseCoopers \& IESE, viewed 06 November, 2012, from http://www. ebcenter.org/_proyectos

Spanos, Y.E., Prastacos, P. \& Poulymenakou, A., 2002, 'The relationship between information and communications technologies adoption and management', Information \& Management 39, 659-675. http://dx.doi.org/10.1016/S03787206(01)00141-0

Srinivasan, R., Lilien, G. \& Rangaswamy, A., 2002, 'Technological opportunism and radical technology adoption: an application to e-business', Journal of Marketing 66(July), 47-60. http://dx.doi.org/10.1509/jmkg.66.3.47.18508

Stensaker, I. \& Falkenberg, J., 2007, 'Making sense of different responses to corporate change', Human Relations 60(1), 137-177. http://dx.doi. org/10.1177/0018726707075287

Sultan, F. \& Chan, L., 2000, 'The adoption of new technology: The case of objectoriented computing in software companies', IEEE Transactions on Engineering Management 47(1), 106-126. http://dx.doi.org/10.1109/17.820730

Tarafdar, M. \& Vaidya, S.D., 2006, 'Challenges in the adoption of e-commerce technologies in India: The role of organisational factors', International Journa of Information Management 26, 428-441. http://dx.doi.org/10.1016/j. ijinfomgt.2006.08.001

Teng, J.T.C., Grover, V. \& Guttler, W., 2002, 'Information technology innovations: general diffusion patterns and its relationships to innovation characteristics', IEEE Transactions on Engineering Management 49(1), 13-27. http://dx.doi. org/10.1109/17.985744

Teo, T.S.H., Tan, M. \& Buk, W.K., 1998, 'A contingency model of internet adoption in Singapore', International Journal of Electronic Commerce 2(2), 95-118. 
Thong, J.Y.L., 1999, 'An integrated model of information systems adoption in small businesses', Journal of Management Information Systems 15(4) 187-214.

Troshani, I. \& Doolin, B., 2005, 'Drivers and inhibitors impacting technology adoption: a qualitative investigation into the Australian experience with XBRL', paper presented at the 18th Bled eConference, Slovenia, 06-08 June 2005.

Vaara, E. \& Whittington, R., 2012, 'Strategy-as-practice: Taking social practices seriously', The Academy of Management Annals 1(March), 1-52.

Venkatesh, V. \& Davis, F.D., 2000, 'A theoretical extension of the technology acceptance model: Four longitudinal field studies', Management Science 46(2), 186-204. http://dx.doi.org/10.1287/mnsc.46.2.186.11926

Walsh, S., Kirchhoff, B.A. \& Newbert, S., 2002, 'Differentiating market strategies for disruptive technologies', Transactions on Engineering Management 49(4), 342-351. http://dx.doi.org/10.1109/TEM.2002.806718
Whittington, R., 2002, 'Practice perspective on strategy: Unifying and developing a field', paper presented at the Academy of Management meeting, Denver, $\mathrm{CO}$, 09-14 August 2002, c1-c6.

Whittington, R., Molloy, E., Mayer, M. \& Smith, A., 2006, 'Practices of strategizing/ organising broadening strategy work and skills', Long Range Planning 39 615-629. http://dx.doi.org/10.1016/j.Irp.2006.10.004

Yetton, P., Sharma, R. \& Southon, G., 1999, 'Successful IS innovation: The contingent contributions of innovation characteristics and implementation process', Journal of Information Technology 14, 53-68. http://dx.doi.org/10.1080/026839699344746

Yin, R.K., 2003, Case study research design and methods, 3rd edn., Sage Publications Inc., Thousand Oaks, CA.

Zahra, S.A. \& Covin, J.G., 1993, 'Business strategy, technology policy and firm performance', Strategic Management Journal 14(6), 451-478. http://dx.doi. org/10.1002/smj.4250140605 